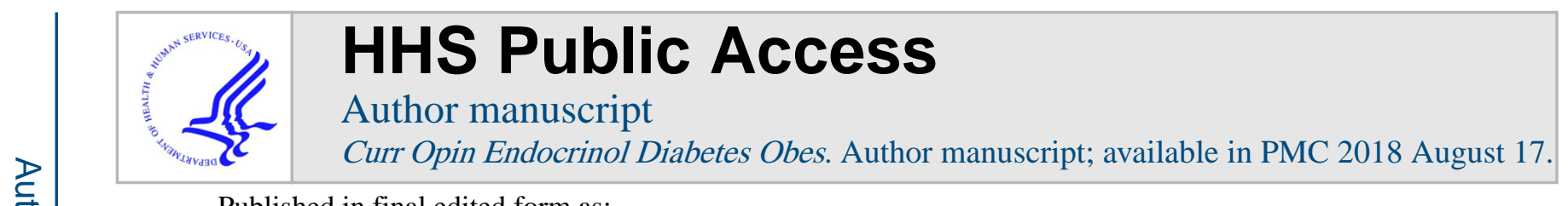

Published in final edited form as:

Curr Opin Endocrinol Diabetes Obes. 2017 February ; 24(1): 67-72. doi:10.1097/MED.

0000000000000310.

\title{
Growth in patients with type 1 diabetes
}

\author{
Deborah M. Mitchell \\ Endocrine Unit and Pediatric Endocrine Unit, Massachusetts General Hospital, Boston, \\ Massachusetts, 02114
}

\begin{abstract}
Purpose of review-As the incidence of type 1 diabetes (T1DM) continues to rise, complications including impairment of childhood growth remain a major concern. This review provides an overview of alterations in growth patterns prior to and after the onset of T1DM.
\end{abstract}

Recent findings-Recent advances in this field include several prospective investigations of height and weight trajectories in children leading up to the development of islet autoimmunity and T1DM as well as evaluations of larger cohorts of T1DM patients to better assess predictors of altered growth. In addition, genetic and metabolic investigations have improved our understanding of the more rare severe growth impairment of Mauriac Syndrome.

Summary-Despite advances in medical care of children with T1DM, growth remains suboptimal in this population and likely reflects ongoing metabolic derangement linked with classic microvascular diabetic complications.

\section{Keywords}

Type 1 diabetes; growth; IGF1; Mauriac syndrome

\section{Introduction}

Childhood growth is under complex endocrine control and is tightly linked to nutrient availability ${ }^{1}$. It is thus not surprising that type 1 diabetes (T1DM), a disorder characterized by profound dysregulation of nutrient metabolism, is associated with impaired growth. This review will summarize what is known about growth trajectories in children both preceding and following T1DM onset as well as our current understanding of the pathophysiology of growth alterations in this population.

\section{Growth prior to the onset of T1DM}

Soon after the discovery of insulin, several investigators noted that, at the time of T1DM onset, children were taller than unaffected peers (reviewed in Drayer) ${ }^{2}$. Subsequent reports have confirmed this observation ${ }^{3-9}$, though some cohorts have found the effect to be more

Contact information: Deborah Mitchell, MD, Endocrine Unit, Massachusetts General Hospital, 50 Blossom St., Boston, MA 02114, Phone: 617-724-2034, Fax: 617-726-1703, dmmitchell@partners.org.

Conflicts of interest: None

Disclosure statement: none 
substantial in boys ${ }^{2,5,9}$ or to children who develop T1DM between ages 5 to approximately 10 years but not children with earlier or later onset of disease ${ }^{7,9}$. Bonfig and colleagues, in a recent large cohort of 22,651 German and Austrian children with T1DM diagnosed between 1980 and 2000, confirm that this phenomenon persists, despite secular changes in the incidence and mean age of onset of diabetes ${ }^{10}$. In their cohort, the mean height standard deviation score (SDS) was $0.22 \pm 1.00$ at disease onset, significantly higher than a national reference base. This effect appears more pronounced in children diagnosed at a younger age, with mean height SDS values of $0.30 \pm 1.00,0.26 \pm 0.99$, and $0.09 \pm 0.98$ among children diagnosed from age $0-5$ years, 6-11 years, and 12-17 years respectively.

Attention has thus turned in recent years to investigations of pre-diagnosis growth velocity and risk of islet autoimmunity and T1DM. In a retrospective study, the EURODIAB collaborative group reported that growth in 499 T1DM patients diagnosed before the age of 15 years was characterized by higher weight and height SDS after 1 month of age as well as higher body mass index (BMI) after 6 months of age compared with local healthy control children ${ }^{11}$. Three prospective studies of children at risk for T1DM based on human leukocyte antigen (HLA) genotype or family history have reported more rapid growth to be associated with islet autoimmunity. In a subset of the German BABYDIAB and BABYDIET cohorts ( $\mathrm{n}=1011)$, a later age at peak infantile BMI (suggestive of less rapid weight gain) was found to be inversely correlated with islet autoimmunity with a hazard ratio (HR) of 0.60 (95\% CI 0.41-0.87) per 2 SD increase in age ${ }^{12}$. In a subsequent analysis of a larger subset of this cohort $(n=2236)$, the authors used a clustering technique to define eight specific growth patterns. While no growth pattern was associated with autoimmunity in the cohort as a whole, when restricted to offspring of non-diabetic mothers ( $\mathrm{n}=942)$, autoimmunity was associated with rapidly increasing BMI SDS as well as with consistently elevated height SDS, while a high length SDS at birth with subsequent regression to average length was found to be protective ${ }^{13}$. In the Diabetes Autoimmunity Study in the Young (DAISY) cohort, in which anthropometric measures were collected after the age of 2 years, height velocity was positively associated with the development of islet autoimmunity (HR $1.63,95 \%$ CI 1.31-2.05) and with progression to T1DM (HR 3.34, 95\% CI 1.73-6.42) ${ }^{14}$. In The Environmental Determinants of Diabetes in the Young (TEDDY) cohort of 7468 at-risk children, islet autoimmunity was positively correlated with weight but not height SDS at 12 months; no correlations however of growth parameters with progression to T1DM were observed $^{15}$. To investigate whether the same relationships held true outside the high-risk population, Magnus and colleagues analyzed 2 Scandinavian birth cohorts comprising over 99,000 children and similarly found that the change in weight from birth to 12 months predicted the development of T1DM ${ }^{16}$. These and similar data have been taken as evidence of the "overload" or "accelerator" hypotheses: namely, that increased growth rates and excess adiposity lead to insulin resistance, promoting $\beta$-cell hyperfunction and increased antigen expression, ultimately leading to both autoimmunity and accelerated $\beta$-cell failure ${ }^{17,18}$. They do not however exclude other explanatory models including shared genetics of growth and islet autoimmunity or diet-associated alterations in the gut microbiome ${ }^{19}$. 


\section{Growth following the onset of T1DM}

Impaired growth velocity, with a decrease in height SDS from disease onset to final adult height, has been a consistent observation in cohorts of patients with $\mathrm{T}_{1} \mathrm{DM}^{7,8,20-23}$. Both pre-pubertal growth velocity as well as the pubertal growth spurt have been reported to be lower in T1DM $7,24,25$. Effect modification by sex has been reported in some studies: in cohorts from the Oxford Regional Prospective Study (ORPS), pubertal growth velocity was more dramatically affected in girls compared with boys ${ }^{7,22}$, while other cohorts have conversely found more significant effects in boys ${ }^{25,26}$. In the largest cohort described to date, Bonfig and colleagues evaluated 1685 patients diagnosed between 1980 and 2000 who had reached near-adult height ${ }^{10}$. Over an average of 9.1 years, height SDS decreased from $0.25 \pm 0.95$ at diagnosis to $-0.16 \pm 0.97$ (females) and $-0.17 \pm 1.00$ (males) at nearadulthood, for an average decrease of 0.41 SDS. Near-adult height SDS did not differ by sex, but was lower among patients with longer duration of disease. In addition, there was a marked difference in effect by glycemic control as measured by HgbAlc, with mean adult height SDS of $0.030,-0.122$, and -0.308 among patients with HgbA1c $<7.0 \%, 7.0-8.0 \%$, and $>8.0 \%$ respectively. This correlation of height velocity with glycemic control has been observed in several other cohorts as well ${ }^{21-25,27}$. Donaghue and colleagues in an Australian cohort found a secular trend of improved growth when comparing children diagnosed from 1974-1990 with those diagnosed from 1991-1995 ${ }^{28}$, likely due to improved treatment options and technologies ${ }^{29}$. However, in resource-poor settings, the magnitude of the effect of T1DM on final height remains more substantial ${ }^{30}$.

\section{Mauriac syndrome}

The most extreme example of growth failure in T1DM is Mauriac syndrome, described initially in 1930, which, in addition to growth failure, is characterized by hepatomegaly due to glycogen accumulation, delayed puberty, and Cushingoid features ${ }^{31}$. While Mauriac syndrome is invariably observed in the setting of poor glycemic control, only a small fraction of T1DM patients with elevated HgbA1c develop the condition, suggesting that additional risk factors must exist. A potential genetic cause was recently described by MacDonald and colleagues who studied a 13 year old boy with Mauriac syndrome severe enough to cause liver impingement on the diaphragm and respiratory distress ${ }^{32}$. Sequential sequencing of candidate genes in the glycogen metabolism pathway revealed a heterozygous mutation of a highly conserved amino acid in the phosphorylase kinase $\gamma$ subunit 2 (PHKG2) gene. Phosphorylase kinase is an activator of glycogen phosphorylase, the enzyme that catalyzes the initial step in glycogenolysis. Mutations in $P H K G 2$ had previously been described to cause glycogen storage disease type IX when found in homozygous or compound heterozygous forms $\mathrm{s}^{33,34}$. The authors overexpressed the mutant form in a human liver cell line and demonstrated decreased phosphorylase kinase activity and inhibition of glycogen breakdown. Notably, the patient's mother had the same mutation but did not have diabetes, and the patient's father had T1DM with poor glycemic control but wildtype PHKG2; neither parent had hepatomegaly or other features of Mauriac syndrome. The authors thus propose a "two-hit" pathophysiologic mechanism: the genetic mutation in phosphorylase kinase exacerbates the well-described inhibition of glycogen phosphorylase by hyperglycemia ${ }^{35}$, leading to severe impairment of glycogen breakdown. While a role for 
this or similar genetic abnormalities in Mauriac syndrome certainly requires validation in additional patients, two recent case series of Mauriac syndrome patients from the United Kingdom and the Netherlands noted elevated fasting lactate in 16/31 (52\%) and 4/4 (100\%) of patients respectively, suggestive of an underlying inherited disorder of metabolism ${ }^{36,37}$. In both these case series, those patients who achieved improved glycemic control had improvement in hepatomegaly and transaminitis, consistent with a role for hyperglycemia in contributing to the pathophysiology. Unexplored as yet is whether such mutations in the absence of poor glycemic control have negative effects on growth or microvascular disease.

\section{Pathophysiology of impaired growth in T1DM}

Longitudinal bone growth proceeds by an orderly differentiation of growth plate chondrocytes from the resting to the proliferative and finally to the hypertrophic stage. Subsequent invasion by blood vessels and ostegenic precursor cells leads to new bone formation and thus bone elongation ${ }^{1}$. This process is critically dependent on elements of the growth hormone (GH)-insulin-like growth factor 1 (IGF1) axis. GH directly stimulates chondrocyte proliferation ${ }^{38}$. GH also stimulates local and hepatic synthesis of IGF1 which acts to promote chondrocyte hypertrophy ${ }^{39,40}$. Dysregulation of the GH-IGF1 axis in T1DM is well-described and is characterized by decreases in circulating IGF1, IGF-binding protein 3 , and GH-binding protein, along with increases in GH and IGF-binding protein $1^{41,42}$. Insulin directly regulates hepatic $\mathrm{GH}$ responsiveness by altering $\mathrm{GH}$ receptor availability as well as downstream signaling ${ }^{43,44}$. Altered IGF1 and binding protein concentrations are thus thought to be secondary to decreased portal vein insulin concentration given that therapeutic administration of insulin in diabetes is via the subcutaneous route. Administration of insulin or intensification of therapy improves but does not normalize these abnormalities ${ }^{45-47}$. Indirect evidence for the importance of portal insulin was provided by Hedman and colleagues who demonstrated that residual $\beta$-cell function was associated with higher IGF1 and lower IGFBP1 concentrations independent of glycemic control ${ }^{48}$. More recent data suggest that this effect may be limited to pre-pubertal children ${ }^{49}$. Direct support for this hypothesis has recently been provided by van Dijk and colleagues who compared patients treated with intraperitoneal insulin pump therapy vs. subcutaneous pump and/or multiple daily injection regimens and found that IGF1 concentrations were higher, though not fully normalized, in those on intraperitoneal therapy, though this relationship did not persist after controlling for total daily dose of insulin ${ }^{50}$.

The lack of normalization of the IGF1 axis by intensive insulin therapy including intraperitoneal insulin may reflect additional metabolic alterations contributing to impaired growth in T1DM. For example, TIDM patients have elevated circulating inflammatory markers including interleukin-6, C-reactive protein, and fibrinogen ${ }^{51}$. These and other inflammatory cytokines can impact growth both by direct effects on the growth plate as well as by suppression of IGF $1^{52}$. In addition, the latest genome-wide association studies have identified over 400 loci determining height. While elements of the GH-IGF axis are implicated, numerous other pathways, including local signaling molecules in the growth plate as well as cartilage matrix proteins have been implicated as well ${ }^{53,54}$. Diabetesassociated alterations in nutrient signaling at the growth plate may have effects on these critical determinants of growth and remain to be explored. 


\section{Clinical implications of impaired growth}

While accumulated evidence clearly indicates that T1DM continues to be associated with decreased height velocity and final adult height, the magnitude of the effect in most reports is fairly moderate. For example, the mean loss of $0.41 \mathrm{SDs}$ found by Bonfig et al. would be equivalent to approximately $2.5-3.0 \mathrm{~cm}$ at final adult height depending on sex and reference population ${ }^{10}$. Furthermore, given that mean height at diagnosis of T1DM is slightly elevated, mean final adult height is only minimally lower than the population average. Given improving but persistently high rates of microvascular complications including severe retinopathy and end stage renal disease as well as the persistent excess cardiovascular mortality among patients with $\mathrm{T} 1 \mathrm{DM}^{55,56}$ moderate effects on adult height may seem to be a relatively minor concern.

Short stature in T1DM, however, has been linked in several reports to microvascular complications, particularly to diabetic nephropathy ${ }^{25,57-61}$. In one of the earliest observations, 181 subjects with T1DM diagnosed in childhood were found to have a mean height SDS of $-0.22 \pm 1.15$, lower than that both of the general population and of their parents and siblings, consistent with several other reports ${ }^{57}$. Notably, the authors reported that height was inversely correlated with severity of both retinopathy and nephropathy. After adjustment for longitudinal glycemic control, this relationship remained significant for retinopathy though not for nephropathy. The UK Microalbuminuria Collaborative Study Group reported that subjects in their cohort who progressed to microalbuminuria were on average $6 \mathrm{~cm}$ shorter than those who did not; height was not an independent predictor of progression however after adjusting for covariates including baseline albumin excretion, blood pressure, and glycemic control ${ }^{59}$. Wadén and colleagues examined data from 2 large cohorts: the Finnish Diabetic Nephropathy Study (FinnDiane, n=3968) and the Diabetes Control and Complications Trial (DCCT, $n=1246)^{61}$. In the Finnish cohort, shorter stature was associated with nephropathy and retinopathy after adjusting for glycemic control and other covariates, but became non-significant after adjusting for duration of diabetes during childhood. In particular, height and nephropathy were associated only in patients who developed diabetes before age 13. In the DCCT cohort, those with height in the lowest quartile had an adjusted hazard ratio of 2.39 (95\% CI 1.34-4.25) for progression to diabetic nephropathy compared to those in quartiles $2-4$, even after adjustment for childhood exposure to diabetes. The incidence of retinopathy was also associated with stature in the DCCT cohort but was no longer significant after adjustment. Most recently, using the ORPS cohort, Marcovecchio and colleagues examined changes in height SDS across puberty in relationship to microalbuminuria and found that height velocity was more substantially impaired in those with microalbuminuria (loss of -0.29 SDs from ages 11 to 18 years) than those with normal albumin excretion (loss of $-0.08 \mathrm{SDs})^{25}$. This relationship persisted after adjustment for sex and duration of disease but became non-significant after adjusting for glycemic control. Overall, these data suggest that impaired growth velocity during childhood is a marker of disease control which may serve as an index of ongoing microvascular disease as well as a harbinger of future risk. Interestingly, there are also reported associations of height with nephropathy in patients not exposed to diabetes during childhood, including those who develop T1DM in adulthood ${ }^{58}$, patients with $\mathrm{T}_{2} \mathrm{DM}^{62}$, and even in non-diabetic 
patients ${ }^{63}$. These data suggest that some of the association between height and nephropathy may be independent of diabetic effects on growth but rather mediated by shared genetic pathways, by in utero exposures affecting both growth and nephron development ${ }^{64}$, or by associations of low birth weight, short stature, and insulin resistance ${ }^{65}$.

In addition, the same alterations in the GH-IGF axis which affect growth velocity in youth with T1DM are likely to be major contributors to the skeletal fragility which is increasingly recognized as a serious complication of $\mathrm{T}^{1} \mathrm{DM}^{66}$. Two recent meta-analyses have demonstrated that adults with T1DM have an over 6-fold increased risk of hip fracture ${ }^{67,68}$, an injury associated with a 5 to 8 -fold excess mortality in the subsequent 3 months as well as substantial morbidity including loss of independence ${ }^{69,70}$. Diminished bone mineral density is observed early in the course of T1DM ${ }^{71,72}$, and a recent study from Weber and colleagues using a large UK database showed for the first time that even children with T1DM are at increased risk of fracture, with hazard ratios of 1.14 (95\% CI 1.01 to 1.29$)$ and 1.35 (95\% CI $1.12-1.63)$ for men and women $<20$ years old respectively ${ }^{73}$. Data from a rodent model in which hepatic IGF1 was deleted showed a $6 \%$ decrease in femoral length, a 9\% decrease in total bone mineral density, and a $26 \%$ loss of cortical bone volume, suggesting that growth and bone density are both sensitive to circulating (endocrine) IGF ${ }^{74}$. Clinically, in one small study of girls ages 12-15 with T1DM, serum IGF1 concentrations positively correlated with estimates of bone strength as measured by peripheral quantitative computed tomography ${ }^{75}$. Intriguingly, 2 recent studies of skeletal microarchitecture in adults with childhood onset T1DM have demonstrated decreased trabecular bone density at the distal radius and tibia ${ }^{76,77}$; in both, effects on bone density were limited to those subjects who had clinical evidence of diabetic microvascular disease. These findings again point to the intimate relationship of compromised growth and bone accrual with classic microvascular disease.

\section{Conclusions and future directions}

Growth velocity is a sensitive sign of health in childhood. Evidence of impaired growth among patients with T1DM is therefore an indication that, despite the many technological advances in the treatment of T1DM, much work remains to be done to optimize care of this vulnerable population. Conversely, the increased growth observed prior to onset may provide clues regarding the triggers for development of diabetes in at-risk patients. As new treatments and technologies emerge, improved growth among children with T1DM may presage substantial lifetime reductions in diabetes-associated complications including microvascular disease and skeletal fragility.

\section{Acknowledgments}

None

Financial support and sponsorship: This work was supported by NIH grant K23DK105350

\section{References}

1. Nilsson O, Marino R, De Luca F, Phillip M, Baron J. Endocrine regulation of the growth plate. Horm Res. 2005; 64(4):157-165. [PubMed: 16205094] 
2. Drayer NM. Height of diabetic children at onset of symptoms. Arch Dis Child. Aug; 1974 49(8): 616-620. [PubMed: 4420915]

3. Songer TJ, LaPorte RE, Tajima N, et al. Height at diagnosis of insulin dependent diabetes in patients and their non-diabetic family members. Br Med J (Clin Res Ed). May 31; 1986 292(6533):14191422.

4. Salardi S, Tonioli S, Tassoni P, Tellarini M, Mazzanti L, Cacciari E. Growth and growth factors in diabetes mellitus. Arch Dis Child. Jan; 1987 62(1):57-62. [PubMed: 3813637]

5. Blom L, Persson LA, Dahlquist G. A high linear growth is associated with an increased risk of childhood diabetes mellitus. Diabetologia. Jun; 1992 35(6):528-533. [PubMed: 1612225]

6. Price DE, Burden AC. Growth of children before onset of diabetes. Diabetes Care. Oct; 1992 15(10):1393-1395. [PubMed: 1425107]

7. Brown M, Ahmed ML, Clayton KL, Dunger DB. Growth during childhood and final height in type 1 diabetes. Diabet Med. Mar; 1994 11(2):182-187. [PubMed: 8200204]

8. Bognetti E, Riva MC, Bonfanti R, Meschi F, Viscardi M, Chiumello G. Growth changes in children and adolescents with short-term diabetes. Diabetes Care. Aug; 1998 21(8):1226-1229. [PubMed: 9702424]

9. Ljungkrantz M, Ludvigsson J, Samuelsson U. Type 1 diabetes: increased height and weight gains in early childhood. Pediatr Diabetes. Jun; 2008 9(3 Pt 2):50-56. [PubMed: 18540867]

10. Bonfig W, Kapellen T, Dost A, et al. Growth in children and adolescents with type 1 diabetes. J Pediatr. Jun; 2012 160(6):900-903 e902. [PubMed: 22244464]

11. Group ESS. Rapid early growth is associated with increased risk of childhood type 1 diabetes in various European populations. Diabetes Care. Oct; 2002 25(10):1755-1760. [PubMed: 12351473]

12. Beyerlein A, Thiering E, Pflueger M, et al. Early infant growth is associated with the risk of islet autoimmunity in genetically susceptible children. Pediatr Diabetes. Nov; 2014 15(7):534-542. [PubMed: 24785566]

13**. Yassouridis C, Leisch F, Winkler C, Ziegler AG, Beyerlein A. Associations of growth patterns and islet autoimmunity in children with increased risk for type 1 diabetes: a functional analysis approach. Pediatr Diabetes. Feb 18.2016 In the BABYDIAB and BABYDIET cohorts, rapid weight gain as well as consistently elevated height was associated with islet autoimmunity while decreasing height percentiles across early childhood was protective.

14. Lamb MM, Yin X, Zerbe GO, et al. Height growth velocity, islet autoimmunity and type 1 diabetes development: the Diabetes Autoimmunity Study in the Young. Diabetologia. Oct; 2009 52(10): 2064-2071. [PubMed: 19547949]

15**. Elding Larsson H, Vehik K, Haller MJ, et al. Growth and Risk for Islet Autoimmunity and Progression to Type 1 Diabetes in Early Childhood: The Environmental Determinants of Diabetes in the Young Study. Diabetes. Jul; 2016 65(7):1988-1995. In the multinational TEDDY cohort of children at risk for T1DM, infantile weight gain is associated with the development of autoimmunity. [PubMed: 26993064]

16**. Magnus MC, Olsen SF, Granstrom C, et al. Infant Growth and Risk of Childhood-Onset Type 1 Diabetes in Children From 2 Scandinavian Birth Cohorts. JAMA pediatrics. Dec.2015 169(12):e153759. In two population-based birth cohorts, infantile weight gain is associated with the development of T1DM. [PubMed: 26642117]

17. Wilkin TJ. The accelerator hypothesis: weight gain as the missing link between Type I and Type II diabetes. Diabetologia. Jul; 2001 44(7):914-922. [PubMed: 11508279]

18. Dahlquist G. Can we slow the rising incidence of childhood-onset autoimmune diabetes? The overload hypothesis. Diabetologia. Jan; 2006 49(1):20-24. [PubMed: 16362279]

19. Kostic AD, Gevers D, Siljander H, et al. The dynamics of the human infant gut microbiome in development and in progression toward type 1 diabetes. Cell host \& microbe. Feb 11; 2015 17(2): 260-273. [PubMed: 25662751]

20. Tattersall RB, Pyke DA. Growth in diabetic children. Studies in identical twins. Lancet. Nov 17; 1973 2(7838):1105-1109. [PubMed: 4128010]

21. Danne T, Kordonouri O, Enders I, Weber B. Factors influencing height and weight development in children with diabetes. Results of the Berlin Retinopathy Study. Diabetes Care. Mar; 1997 20(3): 281-285. [PubMed: 9051372] 
22. Ahmed ML, Connors MH, Drayer NM, Jones JS, Dunger DB. Pubertal growth in IDDM is determined by HbA1c levels, sex, and bone age. Diabetes Care. May; 1998 21(5):831-835. [PubMed: 9589250]

23. Holl RW, Grabert M, Heinze E, Sorgo W, Debatin KM. Age at onset and long-term metabolic control affect height in type-1 diabetes mellitus. Eur J Pediatr. Dec; 1998 157(12):972-977. [PubMed: 9877034]

24. Bizzarri C, Benevento D, Patera IP, et al. Residual beta-cell mass influences growth of prepubertal children with type 1 diabetes. Horm Res Paediatr. 2013; 80(4):287-292. [PubMed: 24051686]

25. Marcovecchio ML, Heywood JJ, Dalton RN, Dunger DB. The contribution of glycemic control to impaired growth during puberty in young people with type 1 diabetes and microalbuminuria. Pediatr Diabetes. Jun; 2014 15(4):303-308. In this report from the well-described Oxford Regional Prospective Study cohort, a correlation of growth and microalbuminuria in children is described, highlighting the link between impaired growth and later diabetic complications. [PubMed: 24320564]

26. Bizzarri C, Benevento D, Giannone G, et al. Sexual dimorphism in growth and insulin-like growth factor-I in children with type 1 diabetes mellitus. Growth Horm IGF Res. Dec; 2014 24(6):256259. [PubMed: 25175911]

27. Gunczler P, Lanes R, Esaa S, Paoli M. Effect of glycemic control on the growth velocity and several metabolic parameters of conventionally treated children with insulin dependent diabetes mellitus. J Pediatr Endocrinol Metab. Nov-Dec;1996 9(6):569-575. [PubMed: 9004171]

28. Donaghue KC, Kordonouri O, Chan A, Silink M. Secular trends in growth in diabetes: are we winning? Arch Dis Child. Feb; 2003 88(2):151-154. [PubMed: 12538321]

29. Tamborlane WV, Bonfig W, Boland E. Recent advances in treatment of youth with Type 1 diabetes: better care through technology. Diabet Med. Nov; 2001 18(11):864-870. [PubMed: 11703429]

30. Elamin A, Hussein O, Tuvemo T. Growth, puberty, and final height in children with Type 1 diabetes. J Diabetes Complications. Jul-Aug;2006 20(4):252-256. [PubMed: 16798477]

31. Kim MS, Quintos JB. Mauriac syndrome: growth failure and type 1 diabetes mellitus. Pediatr Endocrinol Rev. Aug; 2008 5(Suppl 4):989-993. [PubMed: 18806715]

32**. MacDonald MJ, Hasan NM, Ansari IU, Longacre MJ, Kendrick MA, Stoker SW. Discovery of a Genetic Metabolic Cause for Mauriac Syndrome in Type 1 Diabetes. Diabetes. Jul; 2016 65(7): 2051-2059. This case report leads the authors to speculate that Mauriac syndrome arises from severe hyperglycemia/underinsulinization in the setting of mild glycogen metabolism defects. [PubMed: 27207549]

33. Burwinkel B, Bakker HD, Herschkovitz E, Moses SW, Shin YS, Kilimann MW. Mutations in the liver glycogen phosphorylase gene (PYGL) underlying glycogenosis type VI. Am J Hum Genet. Apr; 1998 62(4):785-791. [PubMed: 9529348]

34. Burwinkel B, Rootwelt T, Kvittingen EA, Chakraborty PK, Kilimann MW. Severe phenotype of phosphorylase kinase-deficient liver glycogenosis with mutations in the PHKG2 gene. Pediatr Res. Dec; 2003 54(6):834-839. [PubMed: 12930917]

35. Stalmans W, Laloux M, Hers HG. The interaction of liver phosphorylase a with glucose and AMP. Eur J Biochem. Nov 15; 1974 49(2):415-427. [PubMed: 4442420]

36. Fitzpatrick E, Cotoi C, Quaglia A, Sakellariou S, Ford-Adams ME, Hadzic N. Hepatopathy of Mauriac syndrome: a retrospective review from a tertiary liver centre. Arch Dis Child. Apr; 2014 99(4):354-357. [PubMed: 24412980]

37. Brouwers MC, Ham JC, Wisse E, et al. Elevated lactate levels in patients with poorly regulated type 1 diabetes and glycogenic hepatopathy: a new feature of Mauriac syndrome. Diabetes Care. Feb; 2015 38(2):e11-12. [PubMed: 25614691]

38. Isaksson OG, Jansson JO, Gause IA. Growth hormone stimulates longitudinal bone growth directly. Science. Jun 11; 1982 216(4551):1237-1239. [PubMed: 7079756]

39. Wang J, Zhou J, Bondy CA. Igf1 promotes longitudinal bone growth by insulin-like actions augmenting chondrocyte hypertrophy. FASEB journal : official publication of the Federation of American Societies for Experimental Biology. Nov; 1999 13(14):1985-1990. [PubMed: $10544181]$ 
40. Wang J, Zhou J, Cheng CM, Kopchick JJ, Bondy CA. Evidence supporting dual, IGF-Iindependent and IGF-I-dependent, roles for GH in promoting longitudinal bone growth. $\mathrm{J}$ Endocrinol. Feb; 2004 180(2):247-255. [PubMed: 14765976]

41. Clemmons DR. Metabolic actions of insulin-like growth factor-I in normal physiology and diabetes. Endocrinol Metab Clin North Am. Jun; 2012 41(2):425-443. vii-viii. [PubMed: 22682639]

42. Giannini C, Mohn A, Chiarelli F. Growth abnormalities in children with type 1 diabetes, juvenile chronic arthritis, and asthma. Int J Endocrinol. 2014; 2014:265954. [PubMed: 24648838]

43. Baxter RC, Turtle JR. Regulation of hepatic growth hormone receptors by insulin. Biochem Biophys Res Commun. Sep 29; 1978 84(2):350-357. [PubMed: 214071]

44. Maes M, Underwood LE, Ketelslegers JM. Low serum somatomedin-C in insulin-dependent diabetes: evidence for a postreceptor mechanism. Endocrinology. Jan; 1986 118(1):377-382. [PubMed: 3000746]

45. Amiel SA, Sherwin RS, Hintz RL, Gertner JM, Press CM, Tamborlane WV. Effect of diabetes and its control on insulin-like growth factors in the young subject with type I diabetes. Diabetes. Dec; 1984 33(12):1175-1179. [PubMed: 6389234]

46. Brismar K, Fernqvist-Forbes E, Wahren J, Hall K. Effect of insulin on the hepatic production of insulin-like growth factor-binding protein-1 (IGFBP-1), IGFBP-3, and IGF-I in insulin-dependent diabetes. J Clin Endocrinol Metab. Sep; 1994 79(3):872-878. [PubMed: 7521354]

47. Bereket A, Lang CH, Blethen SL, Ng LC, Wilson TA. Insulin treatment normalizes reduced free insulin-like growth factor-I concentrations in diabetic children. Clin Endocrinol (Oxf). Sep; 1996 45(3):321-326. [PubMed: 8949570]

48. Hedman CA, Frystyk J, Lindstrom T, et al. Residual beta-cell function more than glycemic control determines abnormalities of the insulin-like growth factor system in type 1 diabetes. J Clin Endocrinol Metab. Dec; 2004 89(12):6305-6309. [PubMed: 15579794]

49*. Sorensen JS, Birkebaek NH, Bjerre M, et al. Residual beta-cell function and the insulin-like growth factor system in Danish children and adolescents with type 1 diabetes. J Clin Endocrinol Metab. Mar; 2015 100(3):1053-1061. In pre-pubertal children with T1DM, those with residual beta-cell function have circulating concentrations of IGF1 and its binding proteins almost identical to those of healthy controls. [PubMed: 25532040]

50. van Dijk PR, Logtenberg SJ, Chisalita SI, et al. Different Effects of Intraperitoneal and Subcutaneous Insulin Administration on the GH-IGF-1 Axis in Type 1 Diabetes. J Clin Endocrinol Metab. Jun; 2016 101(6):2493-2501. [PubMed: 27115061]

51. Snell-Bergeon JK, West NA, Mayer-Davis EJ, et al. Inflammatory markers are increased in youth with type 1 diabetes: the SEARCH Case-Control study. J Clin Endocrinol Metab. Jun; 2010 95(6): 2868-2876. [PubMed: 20371668]

52. Sederquist B, Fernandez-Vojvodich P, Zaman F, Savendahl L. Recent research on the growth plate: Impact of inflammatory cytokines on longitudinal bone growth. J Mol Endocrinol. Aug; 2014 53(1):T35-44. [PubMed: 24711646]

53. Lui JC, Nilsson O, Chan Y, et al. Synthesizing genome-wide association studies and expression microarray reveals novel genes that act in the human growth plate to modulate height. Hum Mol Genet. Dec 1; 2012 21(23):5193-5201. [PubMed: 22914739]

54. Wood AR, Esko T, Yang J, et al. Defining the role of common variation in the genomic and biological architecture of adult human height. Nat Genet. Nov; 2014 46(11):1173-1186. [PubMed: 25282103]

55. Lecaire TJ, Klein BE, Howard KP, Lee KE, Klein R. Risk for end-stage renal disease over 25 years in the population-based WESDR cohort. Diabetes Care. Feb; 2014 37(2):381-388. [PubMed: 24026564]

56. Lind M, Svensson AM, Kosiborod M, et al. Glycemic control and excess mortality in type 1 diabetes. N Engl J Med. Nov 20; 2014 371(21):1972-1982. [PubMed: 25409370]

57. Penfold J, Chase HP, Marshall G, Walravens CF, Walravens PA, Garg SK. Final adult height and its relationship to blood glucose control and microvascular complications in IDDM. Diabet Med. Feb; 1995 12(2):129-133. [PubMed: 7743759] 
58. Rossing P, Tarnow L, Nielsen FS, Boelskifte S, Brenner BM, Parving HH. Short stature and diabetic nephropathy. BMJ. Feb 4; 1995 310(6975):296-297. [PubMed: 7866171]

59. Predictors of the development of microalbuminuria in patients with Type 1 diabetes mellitus: a seven-year prospective study. The Microalbuminuria Collaborative Study Group. Diabet Med. Nov; 1999 16(11):918-925. [PubMed: 10588521]

60. Hovind P, Tarnow L, Rossing P, et al. Predictors for the development of microalbuminuria and macroalbuminuria in patients with type 1 diabetes: inception cohort study. BMJ. May 8.2004 328(7448):1105. [PubMed: 15096438]

61. Waden J, Forsblom C, Thorn LM, et al. Adult stature and diabetes complications in patients with type 1 diabetes: the FinnDiane Study and the diabetes control and complications trial. Diabetes. Aug; 2009 58(8):1914-1920. [PubMed: 19491208]

62. Fava S, Azzopardi J, Watkins PJ, Hattersley AT. Adult height and proteinuria in type 2 diabetes. Nephrol Dial Transplant. Mar; 2001 16(3):525-528. [PubMed: 11239026]

63. Gould MM, Mohamed-Ali V, Goubet SA, Yudkin JS, Haines AP. Microalbuminuria: associations with height and sex in non-diabetic subjects. BMJ. Jan 23; 1993 306(6872):240-242. [PubMed: 8443522]

64. Brenner BM, Chertow GM. Congenital oligonephropathy and the etiology of adult hypertension and progressive renal injury. Am J Kidney Dis. Feb; 1994 23(2):171-175. [PubMed: 8311070]

65. Barker DJ. The fetal and infant origins of adult disease. BMJ. Nov 17.1990 301(6761):1111. [PubMed: 2252919]

66. McCabe L, Zhang J, Raehtz S. Understanding the skeletal pathology of type 1 and 2 diabetes mellitus. Crit Rev Eukaryot Gene Expr. 2011; 21(2):187-206. [PubMed: 22077156]

67. Janghorbani M, Van Dam RM, Willett WC, Hu FB. Systematic review of type 1 and type 2 diabetes mellitus and risk of fracture. Am J Epidemiol. Sep 1; 2007 166(5):495-505. [PubMed: 17575306]

68. Vestergaard P. Discrepancies in bone mineral density and fracture risk in patients with type 1 and type 2 diabetes-a meta-analysis. Osteoporos Int. Apr; 2007 18(4):427-444. [PubMed: 17068657]

69. Riggs BL, Melton LJ 3rd. The worldwide problem of osteoporosis: insights afforded by epidemiology. Bone. Nov; 1995 17(5 Suppl):505S-511S. [PubMed: 8573428]

70. Haentjens P, Magaziner J, Colon-Emeric CS, et al. Meta-analysis: excess mortality after hip fracture among older women and men. Ann Intern Med. Mar 16; 2010 152(6):380-390. [PubMed: 20231569]

71. Levin ME, Boisseau VC, Avioli LV. Effects of diabetes mellitus on bone mass in juvenile and adult-onset diabetes. N Engl J Med. Jan 29; 1976 294(5):241-245. [PubMed: 1244549]

72. Mastrandrea LD, Wactawski-Wende J, Donahue RP, Hovey KM, Clark A, Quattrin T. Young women with type 1 diabetes have lower bone mineral density that persists over time. Diabetes Care. Sep; 2008 31(9):1729-1735. [PubMed: 18591404]

73. Weber DR, Haynes K, Leonard MB, Willi SM, Denburg MR. Type 1 diabetes is associated with an increased risk of fracture across the life span: a population-based cohort study using The Health Improvement Network (THIN). Diabetes Care. Oct; 2015 38(10):1913-1920. [PubMed: 26216874]

74. Yakar S, Rosen CJ, Beamer WG, et al. Circulating levels of IGF-1 directly regulate bone growth and density. J Clin Invest. Sep; 2002 110(6):771-781. [PubMed: 12235108]

75. Moyer-Mileur LJ, Slater H, Jordan KC, Murray MA. IGF-1 and IGF-binding proteins and bone mass, geometry, and strength: relation to metabolic control in adolescent girls with type 1 diabetes. J Bone Miner Res. Dec; 2008 23(12):1884-1891. [PubMed: 18665784]

76*. Shanbhogue VV, Hansen S, Frost M, et al. Bone Geometry, Volumetric Density, Microarchitecture, and Estimated Bone Strength Assessed by HR-pQCT in Adult Patients With Type 1 Diabetes Mellitus. J Bone Miner Res. Dec; 2015 30(12):2188-2199. The authors use high-resolution imaging to demonstrate altered trabecular bone microarchitecture in adults with T1DM and show that this phenomenon is restricted to those with diabetic microvascular disease. [PubMed: 26096924] 
77. Abdalrahaman N, McComb C, Foster JE, et al. Deficits in Trabecular Bone Microarchitecture in Young Women With Type 1 Diabetes Mellitus. J Bone Miner Res. Aug; 2015 30(8):1386-1393. [PubMed: 25627460] 


\section{Key points}

- Increased weight and height velocity in infancy and early childhood are correlated with risk of islet autoimmunity and T1DM.

- $\quad$ Among children with T1DM, both pre-pubertal growth and the pubertal growth spurt are impaired.

- Poor glycemic control may interact with mild genetic defects in glycogen metabolism to cause Mauriac syndrome

- $\quad$ Decreased growth in T1DM is correlated with microvascular complications including nephropathy and may share a common pathophysiology with diabetes-associated skeletal fragility. 